\title{
Osmotic dehydration of Braeburn variety apples in the production of sustainable food products**
}

\author{
Agnieszka Ciurzyńska*, Joanna Cichowska, Hanna Kowalska, Kinga Czajkowska, and Andrzej Lenart
}

Faculty of Food Sciences, Department of Food Engineering and Process Management, Warsaw University of Life Sciences, SGGW, 159c Nowoursynowska St., 02-776 Warszawa, Poland

Received February 15, 2017; accepted October 9, 2017

\begin{abstract}
The aim of this work was to investigate the effects of osmotic dehydration conditions on the properties of osmotically pre-treated dried apples. The scope of research included analysing the most important mass exchange coefficients, i.e. water loss, solid gain, reduced water content and water activity, as well as colour changes of the obtained dried product. In the study, apples were osmotically dehydrated in one of two $60 \%$ solutions: sucrose or sucrose with an addition of chokeberry juice concentrate, for 30 and $120 \mathrm{~min}$, in temperatures of 40 and $60^{\circ} \mathrm{C}$. Ultrasound was also used during the first $30 \mathrm{~min}$ of the dehydration process. After osmotic pre-treatment, apples were subjected to innovative convective drying with the puffing effect, and to freeze-drying. Temperature and dehydration time increased the effectiveness of mass exchange during osmotic dehydration. The addition of chokeberry juice concentrate to standard sucrose solution and the use of ultrasound did not change the value of solid gain and reduced water content. Water activity of the dried apple tissue was not significantly changed after osmotic dehydration, while changes in colour were significant.

Keywords: osmotic dehydration, apples, mass exchange, chokeberry juice, sucrose
\end{abstract}

\section{INTRODUCTION}

The use of seasonal fruits as dried snacks resembling chips, e.g. apple chips, might be an interesting solution in food production, providing an alternative to high-calorie products. Apple attractiveness is related to a favourable

*Corresponding author e-mail: agnieszka_ciurzynska@sggw.pl **This work was financially supported by SUSFOOD ERA-Net / NCBiR (National Centre for Research and Development); project No. 5/SH/SUSFOOD1/2014 (2014-2016). The work was also cofinanced by means of a statutory activity subsidy from the Polish Ministry of Science and Higher Education for the Faculty of Food Sciences of Warsaw University of Life Sciences, Poland. content of sugars, acids and biologically valuable ingredients (Raskin and Ripoll, 2004), but the shelf life of this fruit is limited, so appropriate methods of preservation should be chosen to reduce the moisture content and water activity. High temperature and an extended period of drying may cause adverse changes in apples (Mandala et al., 2005), but this effect may be reduced by use of pre-treatment.

Osmotic dehydration appears attractive from the point of view of sustainable development, and is one of the least energy consuming processes that lead to extending the life of food (Astyk, 2009). The efficiency of mass transfer during osmotic dehydration affects the type and structure of raw material, the concentration and type of osmotic solution, the mass ratio of raw material to osmotic solution, and the temperature and process time (Ciurzyńska et al., 2016). Some authors claim that this process has the effect of reducing the water content in the outer layers, leading to a potential difference between adjoining layers of cells, and resulting in the diffusion of water into the intercellular space and through the semipermeable membrane. Moreover, it enhances the penetration of the osmotic solution (Rastogi et al., 2000). Osmotic dehydration, combined with the use of ultrasound, intensifies mass exchange and reduces the pre-treatment and drying times (Fernandes et al., 2008; Ciurzyńska et al., 2014). Oliveira et al. (2011) researched osmotic dehydration of apples in a sucrose solution combined with ultrasound before drying and showed that the drying time was shortened. Ultrasound is thought

(C) 2018 Institute of Agrophysics, Polish Academy of Sciences 
to influence material structure by mechanical interaction with the fruit tissue (Garcia-Perez et al., 2012), which can change mass exchange.

The aim of the study was to investigate the effects of osmotic dehydration conditions on the properties of osmotically pre-treated dried apples. The scope of research included analysis of water loss, dry matter gain, reduced water content, and water activity, as well as colour changes of the obtained dry products.

\section{MATERIALS AND METHODS}

The Braeburn apples were cut into discs (with a diameter of $1.5 \mathrm{~cm}$ and height of $1 \mathrm{~cm}$ ) and osmotically dehydrated in a shaking water bath at 0.92 frequency, using JW. ELECTRONIC type T-SSO. Osmotic dehydration was conducted in one of two $60 \%$ solutions: sucrose or sucrose with chokeberry juice concentrate (1:1), in temperatures of 40 and $60^{\circ} \mathrm{C}$, for 30 and $120 \mathrm{~min}$. The raw material to osmotic solution ratio was 1:4. Samples of apple tissue were also osmotically dehydrated and then ultrasound (MKD-3, MKD Ultrasonic, Stary Konik, Poland) at $21 \mathrm{kHz}$ frequency, was applied for the first $30 \mathrm{~min}$. The osmotically dehydrated apple tissue samples were subsequently rinsed with water, blotted with filter paper and dried by means of two methods. First, a convective drying method was applied for $7 \mathrm{~h}$ at $70^{\circ} \mathrm{C}$, and then the freeze-drying method was used at $25^{\circ} \mathrm{C}$ and $100 \mathrm{MPa}$, for $30 \mathrm{~min}$ after freezing at $-40^{\circ} \mathrm{C}$.

Dry matter content (PN-90/A-75-75101/03) was determined in the SUP-65 WAMED Company drying chamber $\left(50^{\circ} \mathrm{C} / 24 \mathrm{~h}\right)$, and then dried in a vacuum dryer of the HORIZON SPT 200 type $\left(60^{\circ} \mathrm{C} / 2 \mathrm{~h}\right)$. The apple tissue samples were weighed on a RAD WAG WSP $110 / \mathrm{C} / 2$ analytical balance with an accuracy of $0.001 \mathrm{~g}$. The measurements were repeated twice.

Water activity (WA) was determined using the AquaLab apparatus at $25^{\circ} \mathrm{C}$ temperature, in duplicate.
Lightness parameter $\mathrm{L}^{*}$ and chromaticity $\mathrm{a}^{*}$ and $\mathrm{b}$ * parameters were determined according to the Konica Minolta Spectrophotometer CR-300 manual. Measurements were performed in five replicates for each type of the dried apple tissue sample. The total colour difference $(\Delta \mathrm{E})$ was calculated.

Water loss determination enabled calculating the indicators of mass exchange water loss (WL), solid gain (SG), reduced water content $\left(\mathrm{U}_{\text {red }}\right)$ of the dehydrated fruit (Kowalska and Lenart, 2001). During the determination of the value of $U_{\text {red, }}$, a simplification was made, involving the omission of the equilibrium water content $\left(\mathrm{u}_{\mathrm{r}}\right)$ value. This simplification has no significant effect on the results of studies on the kinetics (Figiel, 2013).

Multivariate analysis of ANOVA variance with significance level $\alpha=0.05$ (Statgraphics 4.1 Plus), as well as the test of LSD (least significant difference) via the Fisher procedure, were performed.

\section{RESULTS AND DISCUSSION}

During osmotic dehydration, a steady WL from the fruit was obtained. Depending on the temperature, the extension of dehydration time from 30 to $120 \mathrm{~min}$ brought about a significant WL increase of about $61-64 \%$ for apples dehydrated in the sucrose solution, and of $67-73 \%$ for apples dehydrated in the sucrose solution containing chokeberry concentrate (Fig. 1). With temperature growth from 40 to $60^{\circ} \mathrm{C}$, WL significantly increased by $41-44 \%$ for the sucrose solution, and by $26-30 \%$ for the sucrose containing chokeberry concentrate. The effect of the osmotic solution type on the obtained values was insignificant.

Piasecka et al. (2009) show that dehydration can reduce from 40 to $70 \%$ of the initial water content, and that a temperature increase from 20 to $50^{\circ} \mathrm{C}$ significantly reduces dehydration time. Jain et al. (2011), during the osmotic dehydration of papaya in a sucrose solution $(60 \%)$, obtained

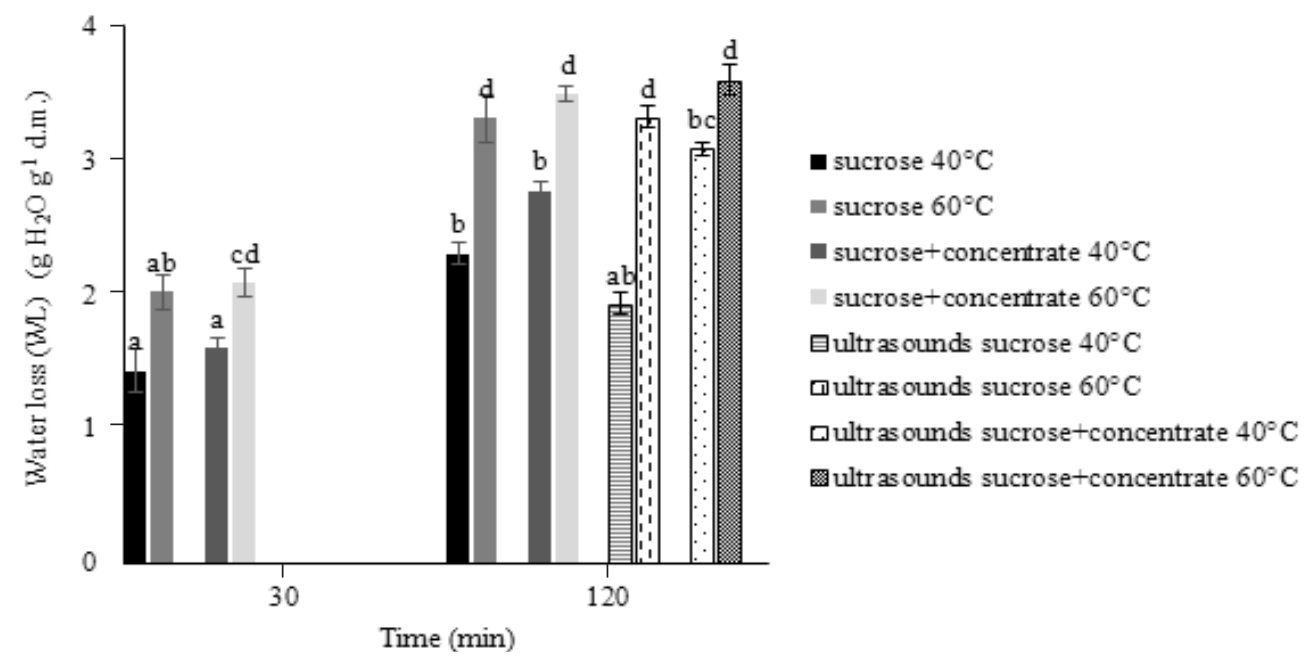

Fig. 1. The effect of osmotic dehydration conditions on water loss (WL) in apples. 


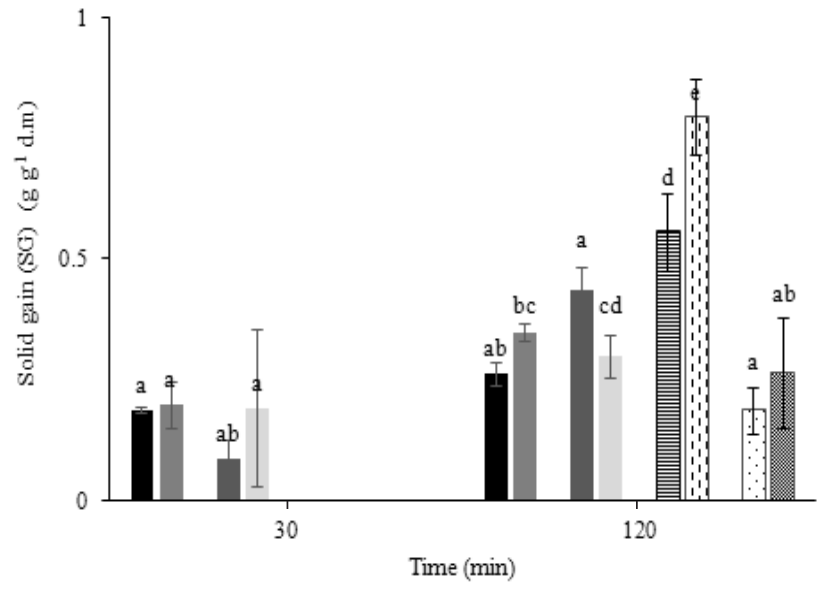

Fig. 2. Effect of osmotic dehydration conditions on solid gain (SG) in apples. Explanation as on Fig. 1.

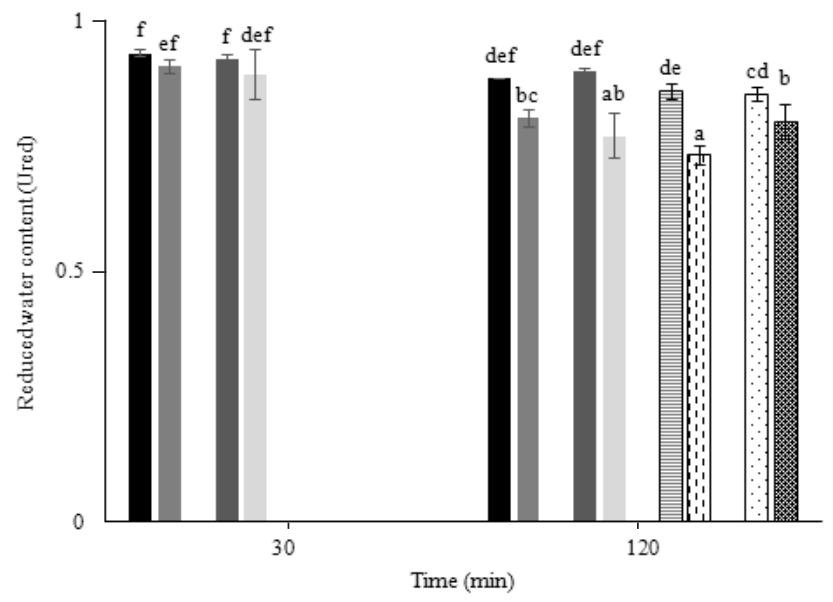

Fig. 3. Effect of osmotic dehydration conditions on reduced water content $\left(\mathrm{U}_{\mathrm{red}}\right)$, in apples. Explanation as on Fig. 1.

a WL at a value of $28 \%$. According to Kowalska and Lenart (2001), the same concentration of high molecular substances induces a lower osmotic pressure and, therefore, the initial rate of discharge is lower than for substances with a smaller molecular weight. Due to the type of the osmotic solution in the presented studies, the differences were not statistically significant.

The use of ultrasound led to a slight reduction in water loss for the sucrose solution $\left(40^{\circ} \mathrm{C}\right)$ and an increase for the sucrose and chokeberry concentrate, in comparison to dehydration without sonification. The increase in temperature generated an increase in WL of $72 \%$ for apples dehydrated in the sucrose alone and of $17 \%$ for the sucrose solution containing chokeberry concentrate, when sonificaton was applied. Simal et al. (1998) observed a water loss increase of $14-27 \%$ for apples treated by ultrasound, in comparison to the untreated samples of apple tissue. Moreover, Siucińska et al. (2015) showed that the use of combined pre-treatment processes (ultrasounds and shaking) induce structure changes which can result in a water loss increase.
Parallel to the WL, an increase in solid gain (SG) was observed. However, an increase in the process duration, temperature and type of the osmotic substance was, in most cases, insignificant and ambiguous. Elongation of the process duration when utilizing the sucrose solution alone resulted in an increase in the SG values by an average of $41-77 \%$ (Fig. 2). The addition of chokeberry concentrate increased the SG values by about $67 \%$, at $40^{\circ} \mathrm{C}$ (120 min) and decreased these values by about $15 \%$, at $60^{\circ} \mathrm{C}(120 \mathrm{~min})$. In addition, the temperature rise increased the SG value by $6-33 \%$ for the sucrose solution alone, and about two times after the first 30 min of dehydration in the sucrose solution containing chokeberry concentrate, but reduced this by $\sim 32 \%$ after $120 \mathrm{~min}$ of dehydration. The largest increase in SG was obtained at the end of the process in the solution of sucrose and chokeberry concentrate at $40^{\circ} \mathrm{C}$ (Fig. 2). Kowalska and Jadczak (2007) show that the addition of ascorbic acid, higher sucrose concentration and temperature rise, increase the dry matter content in dehydrated apples.

The use of ultrasound increased the SG value $\left(0.55 \mathrm{~g} \mathrm{~g}^{-1}\right.$ d.m.) by more than 2 times for the sucrose solution, while for the solution of sucrose and chokeberry concentrate, a reduction by about 2 times at $40^{\circ} \mathrm{C}$ was obtained. The temperature rise increased the SG by $42-43 \%$ for both the sucrose solution and the solution of sucrose and chokeberry concentrate, during dehydration with sonification (Fig. 2).

For the apple tissue samples subjected to ultrasounds, the results of pre-treatment in the sucrose solution were similar to those obtained by Nowacka et al. (2014) for kiwi fruit, wherein the initial use of ultrasounds induced a mass gain of $45 \%$. Simal et al. (1998) obtained a SG ranging from $23 \%\left(40^{\circ} \mathrm{C}\right)$ to $11 \%\left(70^{\circ} \mathrm{C}\right)$ for apples dehydrated in the sucrose solution $\left(40,50,60\right.$ and $\left.70^{\circ} \mathrm{C}\right)$, with ultrasound application $(50 \mathrm{kHz})$.

Osmotic dehydration decreased the $U_{\text {red }}$ in apples. Furthermore, the elongation of process duration at temperatures of 40 and $60^{\circ} \mathrm{C}$ decreased $\mathrm{U}_{\text {red }}$ by $5-11 \%$ (Fig. 3). The temperature rise from 40 to $60^{\circ} \mathrm{C}$ for the sucrose solution resulted in a $U_{\text {red }}$ decrease of 3-9\%. Such differences were statistically significant. However, the effect of the osmotic solution type was insignificant. A beneficial effect of ultrasound on the $U_{\text {red }}$ decrease was observed both at 40 and $60^{\circ} \mathrm{C}$. The obtained values were lower by $3-9 \%$ when compared to those regarding the apple tissue samples without ultrasound treatment. The temperature rise along with ultrasound treatment also decreased the $\mathrm{U}_{\text {red }}$ value. A positive effect of the concentrate addition was obtained at a temperature of $60^{\circ} \mathrm{C}$ (inducing a decrease in $U_{\text {red }}$ of $5 \%$ ), while at lower temperatures, this factor was detrimental (values increased by 2-4\%). Fernandes et al. (2008) also show that ultrasound application increases diffusivity during the osmotic dehydration of papayas. 


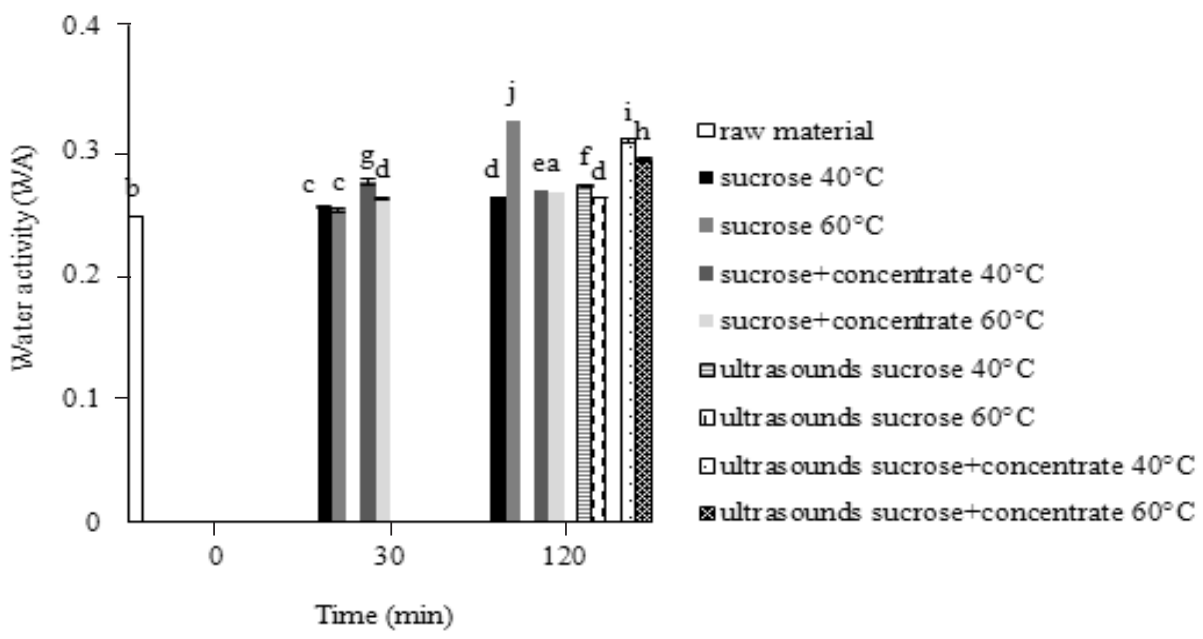

Fig. 4. Effect of osmotic dehydration conditions on water activity of convective dried apples.

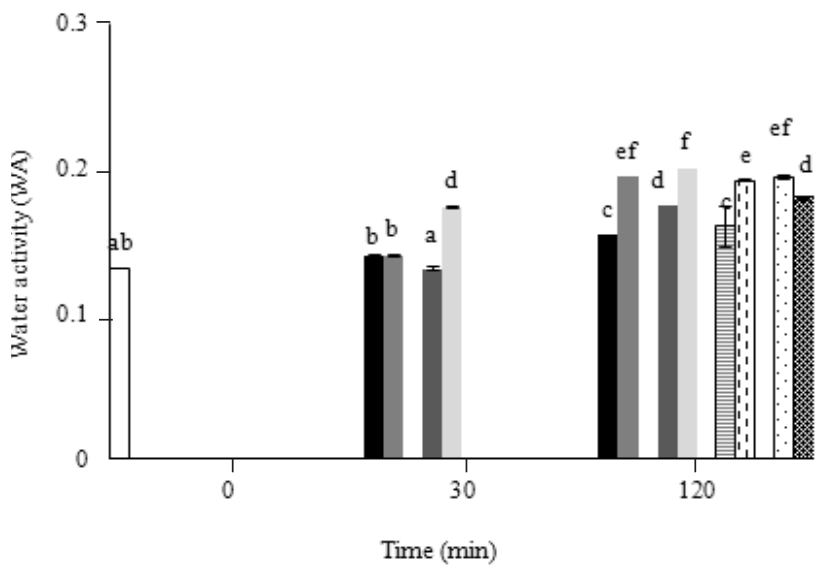

Fig. 5. Effect of osmotic dehydration conditions on water activity of freeze-dried apples. Explanation as on Fig. 4.
Osmotic pre-treatment before convective drying significantly increased water activity (WA) (0.260) as compared to the control samples dried without pre-treatment $(0.246)$ (Fig. 4). A significant effect of time, temperature and a type of the osmotic substance on WA was observed. Antonio et al. (2008) obtained an WA decrease after a longer time of dehydration and with an increase in the osmotic dehydration temperature, while for the tested apple tissue samples in the sucrose solution an increase in WA was observed (Fig. 4). A favourable decrease in water activity (of 25\%), when compared to apples dehydrated without sonification, was observed when utilizing the sucrose solution (at $60^{\circ} \mathrm{C}$ ), before convective drying. Stojanovic et al. (2007) obtained similar relations for blueberries when air-dried and osmotically dehydrated in the sucrose solution, with and without ultrasound application.

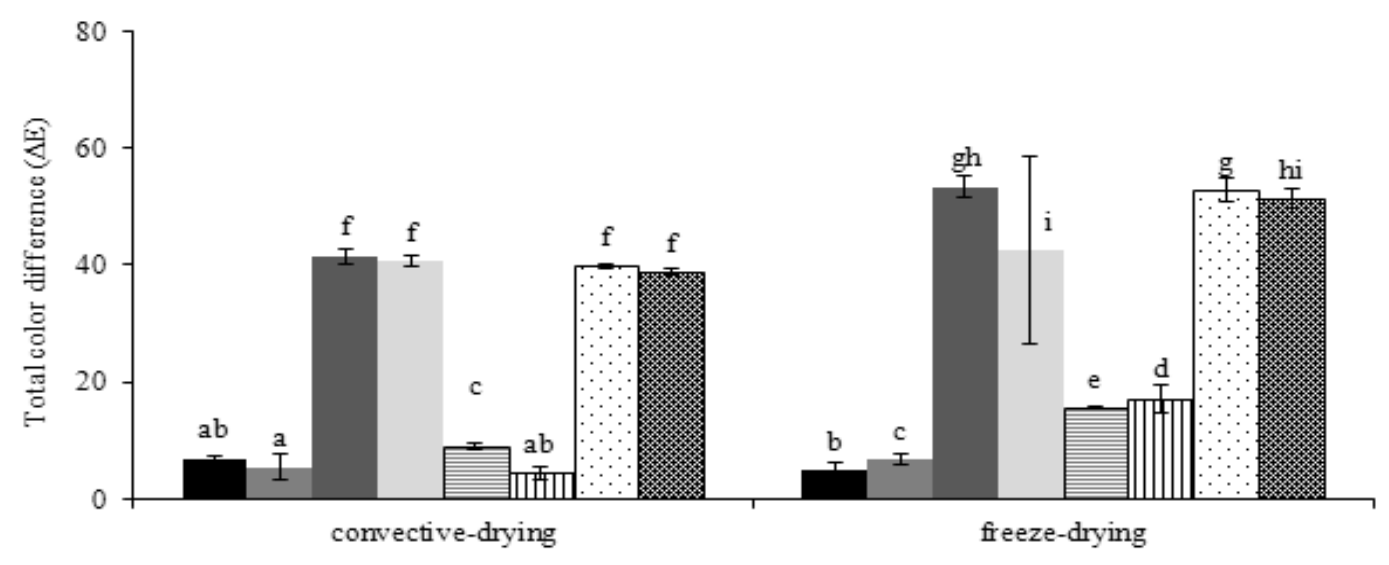

Fig. 6. Effect of osmotic dehydration conditions on toal colour difference $(\Delta \mathrm{E})$ of dried apples. Explanation as on Fig. 1. 
The water activity of the control samples of freezedried apples was lower (0.132) than that of the osmotically pre-treated fruit (Fig. 5). The elongation of the dehydration time and temperature rise as well as the addition of chokeberry juice concentrate to the sucrose solution enhanced the WA value. However, ultrasound application had no significant effect on water activity, while time, temperature, and a type of the osmotic substance did. Furthermore, the use of freeze-drying can significantly reduce the apple water activity when compared to convection drying (Fig. 4).

A significant effect of the drying method, osmotic solution type and temperature on the apple tissue sample colour changes was observed. Osmotic dehydration performed for $120 \mathrm{~min}$ in the sucrose solution changed the colour of the dried apple product. The total colour difference $(\Delta \mathrm{E})$ was 5.4-6.9 for convective drying and 4.9-6.7 for freeze drying (Fig. 6). For the apple tissue samples dehydrated in the sucrose solution containing chokeberry juice concentrate, a further increase in $\Delta \mathrm{E}$ was observed (40.7-41.6 for convection and 42.6-53.4 for freeze-drying). An increase in temperature of the osmotic solution from 40 to $60^{\circ} \mathrm{C}$ significantly raised the $\Delta \mathrm{E}$ for apple samples in the sucrose solution when freeze-dried. In addition, ultrasound application during osmotic dehydration significantly increased the $\Delta \mathrm{E}$ value of freeze-dried apples dehydrated in the sucrose solution.

Pasławska et al. (2010) dried bilberry and raspberry at $50 \mathrm{~Pa}$ and $50^{\circ} \mathrm{C}$. They noted colour differences of $\Delta \mathrm{E}>5$ between the fresh fruit and the dried material. What is more, Stojanovic et al. (2007) showed a significant increase in the $\Delta \mathrm{E}$ value for blueberries dehydrated with sonification before drying. Freeze-drying is considered one of the best methods of low temperature material preservation, but the high value of colour difference index in conducted tests can be explained by the high value of porosity of the freezedried material induced by the process, which significantly increases the $\Delta \mathrm{E}$ value, in comparison to the apple tissue samples that were air-dried.

\section{CONCLUSIONS}

1. In dehydrated apples, an increase in both temperature and osmotic dehydration time results in higher water loss and solid gain.

2. Osmotic dehydration increases water activity of air-dried and freeze-dried apple tissues, in comparison to dehydrated products obtained without osmotic pre-treatment.

3. In dried apples, osmotic dehydration results in a significant colour change.

Conflict of interest: The Authors do not declare conflict of interest.

\section{REFERENCES}

Antonio G.C., Alves D.G. Azoubel P.M., Murr F.E.X., and Park K.J., 2008. Influence of osmotic dehydration and high temperature short time processes on dried sweet potato (Ipomoea batatas Lam.). J. Food Eng., 84, 375-382.

Astyk S., 2009. Dehydration. In: Independence Days: A Guide to Sustainable Food Storage and Preservation (Ed. S. Astyk). New Society Publishers, Canada.

Ciurzyńska A., Kowalska H., Czajkowska K., and Lenart A., 2016. Osmotic dehydration in production of sustainable and healthy food. Trends Food Sci. Technol., 50, 186-192.

Ciurzyńska A., Lenart A., and Gręda J.K., 2014. Effect of pretreatment conditions on content and activity of water and colour of freeze-dried pumpkin. LWT-Food Sci. Technol., 59, 1075-1081.

Ciurzyńska A., Mieszkowska A., Olsiński I., and Lenart A., 2017. The effect of composition and aeration on selected physical and sensory properties of freeze-dried hydrocolloid gels. Food Hydrocolloids, 67, 94-103.

Fernandes F.A.N., Oliveira F.I.P., and Rodrigues S., 2008. Use of ultrasound for dehydration of papaya. Food Bioprocess Technol., 1, 339-345.

Figiel A., 2013. Kinetics of osmotic dehydration of pumpkin slices in codensed juice from quince fruit (in Polish). Zesz. Probl. Post. Nauk Roln., 572, 13-21.

Garcia-Perez J.V., Ortuño C., Puig A., Carcel J.A., and PerezMunuera I., 2012. Enhancement of water transport and microstructural changes by high-intensity ultrasound application on orange peel drying. Food Bioprocess Technol., 5, 2256-2265.

Jain S.K., Verma R.C., Murdia L.K., Jain H.K., and Sharma G.P., 2011. Optimization of process parameters for osmotic dehydration of papaya cubes. J. Food Sci. Technol., 48(2), 211-217.

Kowalska H. and Jadczak S., 2007. Osmotic dehydration of apples in sucrose and ascorbic acid solution. Żywność, Nauka, Technologia, Jakość, 3(52), 119-126.

Kowalska H. and Lenart A., 2001. Mass exchange during osmotic pretreatment of vegetables. J. Food Eng., 49(2), 137-140.

Mandala I.G., Anagnostaras E.F., and Oikonomou C.K., 2005. Influence of osmotic dehydration conditions on apple airdrying kinetics and their quality characteristics. J. Food Eng., 69, 307-316.

Nowacka M., Tylewicz U., Laghi L., Dalla Rosa M., and Witrowa-Rajchert D., 2014. Effect of ultrasound treatment on the water state in kiwifruit during osmotic dehydration. Food Chemistry, 144, 18-25.

Oliveira F.I., Gallão M.I., Rodrigues S., and Fernandes A.N., 2011. Dehydration of malay apple (Syzygium malac-cense L.) using ultrasound as pre-treatment. Food Bioprocess Technol., 4(4), 610-615.

Pasławska M., Stępień B., and Jałoszyński K., 2010. Changes in parameters of berry fruit colour, caused by drying, storage and rehydration. Agric. Eng., 2(120), 95-102.

Piasecka E., Uczciwek M., and Klewicki R., 2009. Osmotic dehydration of fruits in solutions containing fructooligosaccharides. (in Polish). Żywność, Nauka, Technologia, Jakość, 2(63), 138-153.

Raskin I. and Ripoll C., 2004. Can an apple a day keep the doctor away? Current Pharmaceutical Design, 3, 1381-1392. 
Rastogi N.K., Angersbach A., and Knorr D., 2000. Evaluation of mass transfer mechanisms during osmotic treatment of plant materials. J. Food Sci., 65(6), 1016-1019.

Simal S., Benedito J., Sánchez E.S., and Rosselló C., 1998. Use of ultrasound to increase mass transport rates during osmotic dehydration. J. Food Eng., 36(3), 323-336.

Siucińska K., Dyki B., Murgrabia A., Pieczywek P.M., and Konopacka D., 2015. Assessment of changes in structure of dried tissue of sour cherry pretreated using ultrasoundassisted osmotic dehydration. Żywność, Nauka, Technologia, Jakość, 3(100), 123-137.

Stojanovic J. and Silva J.L., 2007. Influence of osmotic concentration, continuous high frequency ultrasound and dehydration on antyoxidations, colur and chemical properties of rabbiteye blueberries. Food Chem., 101, 898-906. 